\title{
Новый класс многомодовых оптических волокон с диаметром сердцевины 100 мкм для компактных мультигигабитных сетей передачи данных разного назначения
}

\author{
$\underline{\text { А.В. Бурдин }}^{1,2,3, *}$, В.А. Бурдин ${ }^{2}$, К.В. Дукельский ${ }^{1}$, О.Е. Наний ${ }^{4}$, \\ T.О. Базаров ${ }^{4}$, В.В. Демидов ${ }^{1}$, А.Е. Жуков ${ }^{2}$, Д.Д. Старых ${ }^{4}$ \\ ${ }^{1}$ АО "НПО ГОИ им. С.И. Вавилова" \\ ${ }^{2}$ Поволжский государственный университет телекоммуникаций и информатики \\ ${ }^{3}$ ООО "ОптоФайбер Лаб" \\ ${ }^{4} O O O$ "T8" \\ *E-mail: bourdine@yandex.ru
}

DOI: 10.31868/RFL2020.136-137

В работе представлены результаты экспериментальных исследований параметров широкополосности и выполненной серии тестов по организации каналов передачи данных, проведенных для изготовленного опытного образца строительной длины нового класса многомодовых оптических волокон (OB), оптимизированных для совместной работы с когерентными источниками оптического излучения, с увеличенным до 100 мкм диаметром сердцевины при "традиционном" для телекоммуникационных ОВ диаметре оболочке 125 мкм протяженностью порядка 500 м. Благодаря успешно воспроизведенной при синтезе преформы ранее разработанной [1] специализированной форме градиентного профиля показателя преломления, для данных ОВ 100/125 достигается существенное снижение дифференциальной модовой задержки (ДМЗ) направляемых мод заданного порядка, по сравнению с известными коммерческими аналогами - многомодовыми ОВ 100/125 и 100/140 [2 - 4]. Полученные новые волоконные световоды в первую очередь, позиционируются как ОВ для мультигигабитных сетей передачи данных разного назначения бортовых и промышленных кабельных систем, для которых характерны экстремально агрессивные условия эксплуатации (вибрации, грязь и взвеси в воздухе, экстремально плотный монтаж и пр.) при достаточно малых протяженностях соединительных линий (десятки, в отдельных случаях - сотни и более метров). Вместе с тем, очевидны и потенциальные возможности применения такого класса волокон непосредственно в различных приложениях лазерной техники / лазерных систем.

Результаты измерений спектральной характеристики коэффициента затухания опытного образца строительной длины ОВ 100/125 приведены на Рис. 1: значения указанного параметра не превышают заявленные 7.0 дБ/км и 4.0 дБ/км на длинах волн 850 нм и 1300/1310 нм, соответственно. На следующем этапе были проведены измерения карты ДМЗ, выполненные в соответствии с ратифицированными стандартами TIA-455-220-A/FOTP-220 и IEC 60793-2-10. Последние предполагают поэтапное снятие (сканирование) полигона импульсных откликов маломодового оптического сигнала, вводимого в торец тестируемого многомодового ОВ через одномодовый согласующий световод сначала центрированно и далее с заданным прецизионным радиальным смещением относительно центра сердцевины. Результаты измерения при сканировании на вводе в диапазоне $0 . .25$ мкм с интервалом 1 мкм, выполненные с помощью станции анализатора ДM3 R2D2 [5] на рабочей длине волны $\lambda=1310$ нм и исходной длительности $\tau_{05}=340$ пс вводимого импульса квазигауссовой формы представлены на Рис. 2. 


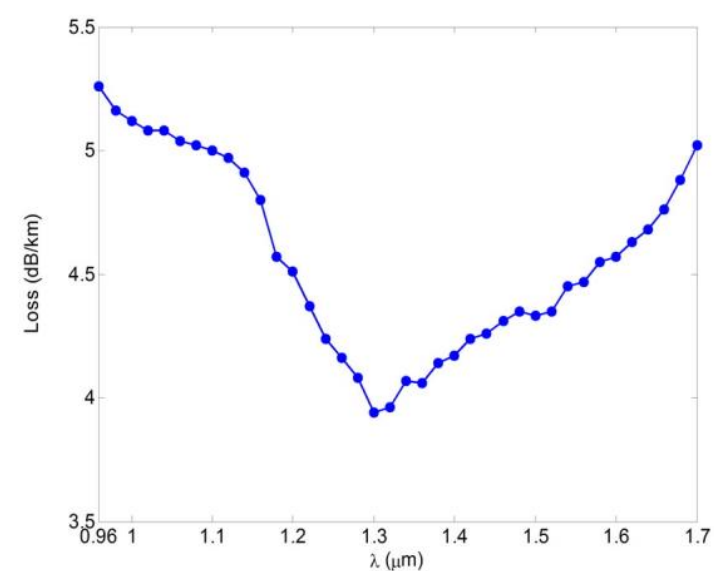

Рис. 1 - Спектральная характеристика коэффициента затухания образца \#02 ОВ 100/125

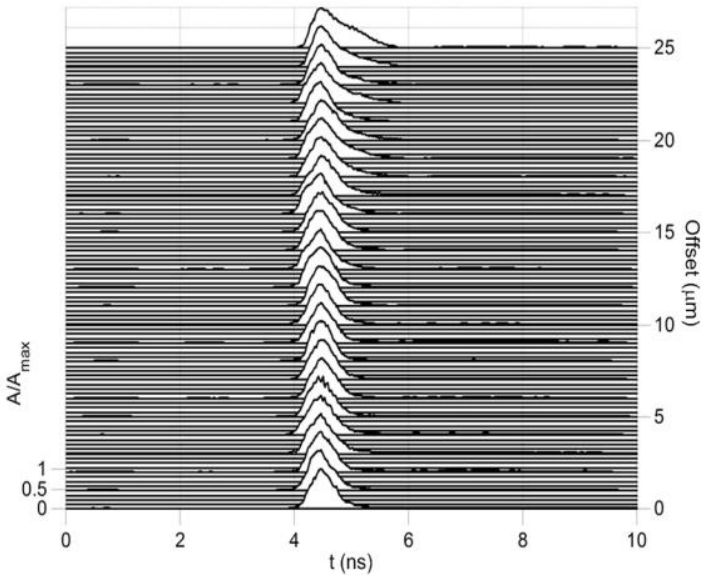

Рис. 2 - Результаты измерения карты ДМЗ ОВ 100/125 \#02 при сканировании на вводе в интервале $0 . .25$ мкм через 1 мкм $(\lambda=1310$ нм$)$

Анализ полученной карты ДМЗ показывает, что на всем интервале сканирования торца исследуемого образца длины ОВ 100/125 огибающая оптического импульса сохраняет свою форму, сигнал не разделяется на отдельные компоненты. Таким образом, можно говорить о непосредственно об оценке дисперсии оптического сигнала на выходе тестируемого ОВ. Расчет последней для каждого импульсного отклика, полученного при соответствующих условиях ввода, проводился с помощью известной методики [6]. Согласно полученным данным, минимальная дисперсия импульса $(150 \ldots 175$ пс) для исследуемого ОВ длиной 500 м соответствует не только центрированному вводу, но и поддерживается даже при значительном радиальном рассогласовании вплоть до 10 мкм. При этом пороговое значение дисперсии многомодового ОВ указанной протяженности 500 м при организации каналов передачи данных, соответствующих спецификациям 1000Base-LX и 10GBase-LR стандартов IEEE 802.3z и 802.3ae, рассчитанное в соответствии с методикой [7], составляет 874.5 пс и 87.1 пс, что, в целом, свидетельствует о высоких потенциальных возможностей применения представленного нового класса многомодовых ОВ 100/125 для указанных приложений.

Вышесказанное подтвердили результаты проведенной серии тестов по организации каналов передачи данных с применением типовых коммерческих трансиверов спецификаций стандарта IEEE 802.3aе: разработанные ОВ 100/125 гарантированного поддерживают скорость передачи 10 Гбит/с на расстояние 300 м.

Исследование выполнено при финансовой поддержке РФФИ, DST, NSFC и NRF в рамках научного проекта № 19-57-80016 БРИКС_т.

\section{Литература}

[1] A.V. Bourdine et al. Photonics, 5(4), 37-1-37-21 (2018)

[2] Draka Communications. DrakaElite ${ }^{\mathrm{TM}}$ Graded-Index Multimode Optical Fiber (100/125 $\left.\mu \mathrm{m}\right)(2020)$

[3] YOFC. Graded Index Multi-mode Fibre (GIMF). Product Catalog (2020)

[4] Nufern. Multimode Fibers. Products (2020)

[5] А.В. Бурдин, Фотон-Экспресс, 5-6(69-70), 20 - 22 (2008)

[6] Дж. Гауэр, Оптические системы связи, М.: Радио и Связь (1989)

[7] D. Cunningham et al. IEEE 802.3z Task Force Presentation Materials, 03 (1997) 